\title{
Styles of pain coping predict cardiovascular function following a cold pressor test
}

\author{
Robert R Edwards $\mathrm{PhD}^{1}$, Roger B Fillingim $\mathrm{PhD}^{2}$
}

RR Edwards, RB Fillingim. Styles of pain coping predict cardiovascular function following a cold pressor test. Pain Res Manage 2005;10(4):219-222.

BACKGROUND: While many studies have examined the impact of pain-related coping in adjustment to chronic pain, relatively few have evaluated the physiological consequences of differences in paincoping styles.

OBJECTIVE: The association between strategies for coping with pain and cardiovascular functioning following exposure to painfully cold water was evaluated.

METHODS: Impedance cardiography was used to assess cardiovascular functioning in 50 healthy subjects before and after a cold pressor test.

RESULTS: The self-reported use of active pain-coping strategies was associated with reductions in mean arterial pressure and cardiac contractility from pre- to post-cold pressor. In contrast, higher levels of pain catastrophizing were related to increases in cardiac contractility following acute cold pain. Importantly, coping variables predicted cardiovascular responses, whereas characteristics of the noxious stimulus (pain tolerance time and pain ratings) did not.

CONCLUSIONS: These findings highlight the importance of coping styles in shaping physiological responses to pain and suggest that interventions targeting increases in adaptive coping and decreases in pain catastrophizing may reduce pain's adverse impact.

Key Words: Cardiovascular; Catastrophizing; Cold pressor; Coping; Impedance cardiography; Pain

\section{Les types d'affrontement de la douleur prédisent la fonction cardiovasculaire après une épreuve au froid}

\begin{abstract}
HISTORIQUE : De nombreuses études portent sur les répercussions de l'affrontement de la douleur sur l'adaptation à la douleur chronique, mais relativement peu d'études traitent des conséquences physiologiques des différences de types d'affrontement de la douleur.

OBJECTIF : L'association entre les stratégies d'affrontement de la douleur et le fonctionnement cardiovasculaire après l'exposition à l'eau douloureusement froide a été évaluée.

MÉTHODOLOGIE : La cardiographie d'impédance a été utilisée pour évaluer le fonctionnement cardiovasculaire de 50 sujets témoins avant et après une épreuve au froid.

RÉSULTATS : L'utilisation déclarée par les intéressés de stratégies actives pour affronter la douleur s'associait à des diminutions de la tension artérielle moyenne et de la contractilité cardiaque avant et après l'épreuve au froid. Par contre, des taux plus élevés de catastrophisation de la douleur étaient reliés à des augmentations de la contractilité cardiaque après une douleur aiguë au froid. Il est important de souligner que les variables reliées à l'affrontement de la douleur prédisaient les réponses cardiovasculaires, contrairement aux caractéristiques des stimuli nuisibles (p. ex., temps de tolérance à la douleur et évaluation de la douleur).

CONCLUSIONS : Ces observations soulignent l'importance du type d'affrontement de la douleur dans le modelage des réponses physiologiques à la douleur et laissent supposer que les interventions ciblant des augmentations de l'affrontement adaptatif et des diminutions de la catastrophisation de la douleur pourraient réduire les répercussions négatives de la douleur.
\end{abstract}

$\mathrm{H}$ ow individuals cope with pain is a consistent predictor of important clinical outcomes including pain severity, physical disability and psychological adjustment (1). Some have argued that the most robust predictors of outcome are maladaptive coping strategies (2), among which catastrophizing, a negative emotional and cognitive response to pain involving elements of magnification, helplessness and pessimism (3), is most prominent. The frequency of catastrophizing is consistently positively correlated with pain, negative affect and disability across many chronically painful conditions (3).

There are fewer laboratory-based investigations of painrelated coping than there are chronic pain studies, but cross-sectional relationships between catastrophizing and experimental pain responses have been reported, with higher levels of catastrophizing being associated with higher pain ratings (4-6). In general, these experimental studies focus on self-reported pain responses (eg, pain ratings or pain tolerance); however, pain has well-documented physiological consequences (eg, enhanced cardiovascular activity, suppression of immune function and release of cortisol) as well (7), and these may be equally important measures of outcome. In particular, cardiovascular-related health problems are often comorbid with chronic pain (8-10), but we know relatively little about how pain-coping styles affect pain-associated blood pressure (BP) reactivity and recovery. Studying BP reactivity and recovery in acute pain models is important, because BP responses to the cold pressor (CP) task predict the later development of hypertension and other important cardiovascular end points $(11,12)$. In the present study, we used impedance cardiography (ICG) to assess participants before and after undergoing a CP task to study the association between pain-coping styles and cardiovascular recovery. We hypothesized that higher levels of pain catastrophizing would be associated with prolonged reactivity, while greater use of active cognitive coping would be related to more rapid and complete recovery.

${ }^{1}$ Department of Psychiatry, Johns Hopkins University School of Medicine, Baltimore, Maryland, USA; ${ }^{2}$ College of Dentistry and Veterans Affairs Medical Center, University of Florida, Gainesville, Florida, USA

Correspondence: Dr Robert R Edwards, Johns Hopkins University School of Medicine, 600 North Wolfe Street, Meyer 1-101, Baltimore, Maryland 21287, USA. Telephone 410-614-3396, fax 410-614-3366, e-mail Redwar10@jhmi.edu 
TABLE 1

Measures of cardiovascular functioning, mood and paincoping $(n=50)$

\begin{tabular}{lccc}
\hline & $\begin{array}{c}\text { Baseline } \\
\text { (pre-CP) }\end{array}$ & Post-CP & $\begin{array}{c}\boldsymbol{t} \text { test for } \\
\text { change }\end{array}$ \\
\hline Mean arterial pressure & $93.0 \pm 11.4$ & $94.4 \pm 11.9$ & $0.8(\mathrm{NS})$ \\
Stroke volume & $118.9 \pm 55.0$ & $120.6 \pm 55.0$ & $1.3(\mathrm{NS})$ \\
Heather index & $9.9 \pm 3.7$ & $10.0 \pm 3.8$ & $0.3(\mathrm{NS})$ \\
Measure & & & \\
\hline Elated-depressed (POMS) & $24.3 \pm 5.4$ & & \\
Diverting attention (CSQ) & $2.1 \pm 1.5$ & & \\
Reinterpreting pain (CSQ) & $1.0 \pm 1.0$ & & \\
Coping self-statements (CSQ) & $3.2 \pm 1.3$ & & \\
lgnoring pain (CSQ) & $2.5 \pm 1.5$ & & \\
Catastrophizing (CSQ) & $1.0 \pm 0.9$ & & \\
\hline
\end{tabular}

Data are presented as mean $\pm S D$. CP Cold pressor; CSQ Coping strategies questionnaire; NS Not significant; POMS Profile of mood states

\section{METHODS}

\section{Participants}

Participants were 50 (25 women, 25 men) undergraduate students (mean age $20.3 \pm 4.0$ years; $48 \%$ black and $36 \%$ white) who participated in the experiment for course credit. Subjects were excluded if they reported major medical conditions or significant health risks (eg, cardiac abnormalities or diabetes), current pain treatment or current use of prescription analgesics, tranquilizers, antidepressants or other centrally acting agents. All procedures were approved by Johns Hopkins University's Institutional Review Board.

\section{Questionnaires}

Coping strategies questionnaire: The coping strategies questionnaire (CSQ) is the most commonly used instrument to assess pain coping (13). Its 48 items measure primarily cognitive dimensions of pain-related coping (ie, catastrophizing; diverting attention; coping self-statements; reinterpreting pain; and ignoring pain sensations). Participants rated the frequency in which they used specific coping strategies on a seven-point Likert scale. The CSQ is well validated (14) for use in both pain patients and healthy adults, and CSQ responses correlate significantly with in vivo reports of coping behaviours (15). Diverting attention, coping self-statements, reinterpreting pain and ignoring pain sensations subscales were averaged, which were significantly intercorrelated (all $\mathrm{r}$ values $>0.34$, $\mathrm{P}$ values $<0.01$, mean $\mathrm{r}=0.40$ ) to form a composite active coping scale (16).

Profile of mood states: The profile of mood states (POMS) (17) consisted of 72 mood related words; subjects indicate the extent to which each item described their mood. The elateddepressed subscale was used; it is a measure of recent negative emotions, which shows good psychometric properties and sensitivity in studies of stress (18).

\section{Procedures}

Upon arrival at the laboratory, subjects provided written and verbal informed consent and then completed the CSQ and POMS. Next, subjects were instrumented for ICG. Subjects relaxed comfortably in a semireclined position for $5 \mathrm{~min}$, then $5 \mathrm{~min}$ of baseline data were collected. Following collection of baseline cardiovascular data, subjects underwent a CP task, during which the right hand was immersed in a circulating water bath (Neslab, RTE-111, USA) maintained at $5^{\circ} \mathrm{C}$. Standardized instructions for the procedure directed participants to keep their hands in the water for as long as possible but explained that if the sensations became intolerable, participants could remove their hands at any time. Each immersion lasted for a maximum of $4 \mathrm{~min}$, though participants were not informed of this time limit. The time to cold pain tolerance (CPTO) was recorded in seconds. After withdrawal of the hand, participants rated the maximum pain intensity and pain unpleasantness experienced during $\mathrm{CP}$ on a scale of 0 to 20 . After finishing the CP procedure, the subjects relaxed comfortably for $5 \mathrm{~min}$; then, another 5 min cardiovascular assessment took place (ie, the post-CP assessment).

Coping as a predictor of cardiovascular reactivity to the $\mathrm{CP}$ was the intended study objective, but the majority of participants removed their hands from the water bath before a reading could be taken (approximately $45 \mathrm{~s}$ are required to obtain an ICG reading with the devices used). Therefore, the changes in cardiovascular functioning from pre- to post-CP were studied instead.

BP was measured using a Dinamap monitor (Critikon, USA); additional cardiovascular measures were assessed using an ICG system (CIC-1000, Sorba Medical System Inc, USA) with placement of spot electrodes following standard guidelines (19), as in previous CP studies $(20,21)$. ICG uses a high-frequency current to monitor the electrical resistance of the thorax to assess a variety of contraction-related events throughout the cardiac cycle (22). The ICG signal's waveforms are then ensemble-averaged, and rates of change and peak values of aortic blood flow are derived. The CIC-1000 system averages waveforms over $30 \mathrm{~s}$ epochs to calculate indices of fluid volume, cardiac timing and cardiac contractility, etc. In the study, associations between pain-coping strategies and the following variables were assessed: pre- to post-CP changes in mean arterial pressure (MAP); stroke volume (SV); and the Heather index (HI), a measure of contractility (23). ICG provides reliable and valid data both for within- and between-group comparisons of hemodynamic profiles $(19,24)$.

\section{Data reduction and analysis}

Descriptive statistics are reported as means \pm SD. Measures of cardiovascular function consist of mean values for each ensemble-averaged epoch within a given $5 \mathrm{~min}$ period. The significance of temporal changes was determined by repeated measures ANOVA, with significance set at alpha $=0.05$. Cross-sectional relationships between continuous variables were examined with Pearson correlations, while predictors of changes (baseline to post-CP) in cardiovascular variables were assessed with hierarchical multiple regression. The effect of coping was assessed only after controlling for baseline cardiovascular function, CPTO and depressed mood.

\section{RESULTS}

As expected, values for ICG-derived variables were within the normal range; no significant changes were observed from pre- to post-CP (see Table 1). Mean \pm SD CP tolerance was $39.9 \pm 57.6 \mathrm{~s}$ (range $4 \mathrm{~s}$ to $240 \mathrm{~s}$ ). Pain ratings for the CP were high; mean pain intensity was $17.2 \pm 2.6$ on a 0 to 20 scale and mean pain unpleasantness was $16.9 \pm 3.5$. In general, mood was moderately positive and the frequency of catastrophizing was low compared with values reported for chronic pain patients. Interestingly, catastrophizing and active coping were not significantly associated with either CPTO or cold pain ratings (all $\mathrm{P}>0.10$ ), as previously observed (25). Moreover, CPTO and cold pain ratings did not show significant zero-order correlations with changes in cardiovascular 


\begin{tabular}{|c|c|c|c|c|c|}
\hline Step & Variable & $R^{2}$ change & F change & Standardized $\beta$ & $\mathbf{P}$ \\
\hline 1 & Pre-CP HI & 0.09 & 4.9 & -0.30 & 0.03 \\
\hline 2 & $\mathrm{CP}$ tolerance & 0.01 & 0.4 & -0.09 & 0.55 \\
\hline 3 & POMS depression & 0.04 & 2.2 & 0.21 & 0.15 \\
\hline 4 & Active coping & 0.06 & 3.1 & -0.26 & 0.05 \\
\hline 5 & Catastrophizing & 0.11 & 6.6 & 0.35 & 0.01 \\
\hline
\end{tabular}

Final model: $F(5,44)=3.8, P<0.05, R^{2}=0.31$. Negative standardized beta $(\beta)$ weights indicate an inverse relationship between the variable in question and change scores for the HI (post-CP minus pre-CP). POMS Profile of mood states

measures. Means and SDs for study variables are presented in Table 1.

Predicting cardiovascular changes following the $\mathrm{CP}$ test Sex, ethnicity and age were not related to baseline MAP, SV or the $\mathrm{HI}$ (all $\mathrm{P}>0.10$ ). In the regression predicting changes in SV, baseline SV, CPTO, POMS depression scores and catastrophizing, all failed to contribute significantly to change scores, and the global model was nonsignificant. The reported frequency of active coping did approach significance $(\mathrm{P}=0.07)$, with more frequent use tending to be associated with post-CP reductions in SV.

In the models predicting changes in MAP and the $\mathrm{HI}$, after controlling for baseline values, CPTO and depression, active coping was significantly associated with reductions in MAP and the HI, while catastrophizing predicted increases in the $\mathrm{HI}$ from pre- to post-CP (Tables 2 and 3).

\section{DISCUSSION}

In the present study of healthy young adults, styles of pain coping were important predictors of cardiovascular recovery following an acute noxious stimulus. Specifically, greater self-reported use of active coping strategies was associated with reductions in MAP and the $\mathrm{HI}$, and catastrophizing was an equally strong predictor of increases in the $\mathrm{HI}$ in the post- $\mathrm{CP}$ period. Catastrophizing is only modestly correlated with the use of other coping strategies (14) and is processed by distinct brain circuits (26), so it is not surprising that catastrophizing and active coping show slightly different patterns of association with different cardiovascular parameters.

Because the overall means for MAP and the HI had returned to baseline values by the post-CP assessment, we should emphasize that this is a study of individual differences in recovery (ie, some individuals showed post-CP elevations, some had returned to baseline and some were below baseline values). Importantly, these associations between pain coping and changes in cardiovascular functioning were observed after controlling for recent mood, suggesting that this was not simply an effect of affective state. We should also point out that the duration of cold water exposure and ratings of its painfulness were unrelated to these changes, indicating that paincoping activities, especially cognitive processes, may be more important determinants of physiological responses to pain than are characteristics of the noxious stimulus. Other researchers (11) have reported similarly large individual differences in cardiovascular responses to a standardized noxious stimulus, and such differences may be partially explained by the use of differing coping strategies across individuals. Future work in this area should also include assessment of in vivo coping

TABLE 3
$\begin{aligned} & \text { Predicting changes in mean arterial pressure (MAP) from } \\
& \text { pre- to post-cold } \text { pressor }(\mathbf{C P})(\mathbf{n}=\mathbf{5 0})\end{aligned}$
\begin{tabular}{llllll}
\hline Step Variable & $\mathbf{R}^{2}$ change & $\mathbf{F}$ change & Standardized $\boldsymbol{\beta}$ & $\mathbf{P}$ \\
\hline 1 & Pre-CP MAP & 0.22 & 13.4 & -0.47 & 0.001 \\
2 & CP tolerance & 0.00 & 0.1 & -0.04 & 0.76 \\
3 & POMS depression & 0.00 & 0.2 & 0.05 & 0.69 \\
4 & Active coping & 0.11 & 6.5 & -0.32 & 0.01 \\
5 & Catastrophizing & 0.00 & 0.1 & 0.03 & 0.82
\end{tabular}

Final model: $F(5,44)=3.8, \quad P<0.01, \quad R^{2}=0.33$. Negative standardized beta weights indicate an inverse relationship between the variable in question and change scores for MAP (post-CP minus pre-CP). POMS Profile of mood states

responses during the experience of pain, because these measures show stronger associations with perceptions of the painfulness of particular stimuli (27).

Other recent evidence has linked coping processes with physiological outcomes in the context of pain. Fibromyalgia patients scoring high on a measure of catastrophizing showed enhanced activation in the anterior cingulate cortex and other regions associated with the affective dimension of pain (26); higher levels of brain activity in these areas have been shown to differentiate highly pain-sensitive individuals from less pain-sensitive individuals (28). Previous work (29) in rheumatoid arthritis patients has also documented prospective associations between pain catastrophizing and disease activity, with higher catastrophizing predicting worsening joint swelling over the course of six weeks. Finally, we have recently shown (30) that catastrophizing is prospectively related to prolongation of sensitization following acute dental pain, suggesting that coping styles have long-term effects on the central nervous system's processing of pain.

Although we were not able to directly assess mediators of the observed effects, one may speculate that catastrophizing and low levels of adaptive coping may result in slower habituation to cold pain. High catastrophizers are slower to disengage their attention from pain (31), implying that catastrophizers might have continued attending to residual sensations after the $\mathrm{CP}$ task was over. Paralleling the results, other laboratory studies have shown that increasing the uncontrollability of pain (a feature of catastrophizing) produces increases in cardiac reactivity (32). Finally, interpretations of pain related to tissue damage (33) might have maintained elevated cardiovascular activity among those who catastrophized or exhibited a limited repertoire of adaptive pain coping skills.

Multiple limitations of the study require consideration. First, we were unable to assess the impact of coping on cardiovascular reactivity to pain; though the construct of recovery is equally important, future investigations may benefit from studying both together. Second, we did not assess responses to non-noxious cold and,thus, we were unable to determine whether these effects are pain specific or whether they would apply to any cardiovascular challenge (eg, exposure to cold ambient air temperatures). Third, in vivo pain coping during the $\mathrm{CP}$ task was not assessed, rendering the study's conclusions somewhat speculative. However, the CSQ has been used in previous work with the CP test (4), and diary studies have reported significant, moderate associations between CSQ responses (ie, a general measure of habitual pain-coping) and in vivo, diary-based reports of pain coping (15). Fourth, this was a healthy sample exhibiting relatively low levels of catastrophizing, the effects of which may be 
magnified in a clinical sample. Finally, participants underwent a very brief period of noxious stimulation, over which they had complete control; this situation is only marginally analogous to that of patients in chronic pain, and demonstrating its clinical relevance requires further investigation.

Despite its limitations, the present work adds to the literature linking coping processes with pain-related physiological outcomes. At least one previous study (34) has suggested that active cognitive coping predicted reduced cardiovascular reactivity to pain, though prior research has not generally examined catastrophizing. It is clear that catastrophizing is prospectively associated with worsening depression and increasing disability (3). The present findings suggest the possibility that higher levels of catastrophizing and lower levels of active coping may also be associated, over the long term, with

\section{REFERENCES}

1. Turk DC, Okifuji A. Psychological factors in chronic pain: Evolution and revolution. J Consult Clin Psychol 2002;70:678-90.

2. Geisser ME, Robinson ME, Riley JL. Pain beliefs, coping and adjustment to chronic pain: Let's focus more on the negative. Pain Forum 1999;8:161-8.

3. Sullivan MJ, Thorn B, Haythornthwaite JA, et al. Theoretical perspectives on the relation between catastrophizing and pain. Clin J Pain 2001;17:52-64.

4. Geisser ME, Robinson ME, Pickren WE. Differences in cognitive coping strategies among pain-sensitive and pain-tolerant individuals on the cold-pressor test. Behav Ther 1992;23:31-41.

5. Geisser ME, Casey KL, Brucksch CB, Ribbens CM, Appleton BB, Crofford LJ. Perception of noxious and innocuous heat stimulation among healthy women and women with fibromyalgia: Association with mood, somatic focus, and catastrophizing. Pain 2003;102:243-50.

6. France CR, France JL, al'Absi M, Ring C, McIntyre D. Catastrophizing is related to pain ratings, but not nociceptive flexion reflex threshold. Pain 2002;99:459-63.

7. Donaldson GW, Chapman CR, Nakamura Y, Bradshaw DH, Jacobson RC, Chapman CN. Pain and the defense response: Structural equation modeling reveals a coordinated psychophysiological response to increasing painful stimulation. Pain 2003;102:97-108.

8. Cote P, Cassidy JD, Carroll L. The factors associated with neck pain and its related disability in the Saskatchewan population. Spine 2000;25:1109-17.

9. Tennant F, Hermann L. Evidence of a clinical neuroendocrine syndrome in severe chronic pain. Pain Med 2001;2:252-3. (Abst)

10. Wolfe F, Michaud K. Severe rheumatoid arthritis (RA), worse outcomes, comorbid illness, and sociodemographic disadvantage characterize RA patients with fibromyalgia. J Rheumatol 2004;31:695-700.

11. Matthews KA, Katholi CR, McCreath H, et al. Blood pressure reactivity to psychological stress predicts hypertension in the CARDIA study. Circulation 2004;110:74-8.

12. Matthews KA, Salomon K, Brady SS, Allen MT. Cardiovascular reactivity to stress predicts future blood pressure in adolescence. Psychosom Med 2003;65:410-5.

13. Rosenstiel AK, Keefe FJ. The use of coping strategies in chronic low back pain patients: Relationship to patient characteristics and current adjustment. Pain 1983;17:33-44.

14. Hastie BA, Riley JL 3rd, Fillingim RB. Ethnic differences in pain coping: Factor structure of the coping strategies questionnaire and coping strategies questionnaire-revised. J Pain 2004;5:304-16.

15. Peters ML, Sorbi MJ, Kruise DA, Kerssens JJ, Verhaak PF, Bensing JM. Electronic diary assessment of pain, disability and psychological adaptation in patients differing in duration of pain. Pain 2000;84:181-92.

16. Snow-Turek AL, Norris MP, Tan G. Active and passive coping strategies in chronic pain patients. Pain 1996;64:455-62.

17. McNair DM, Lorr M, Droppleman LF. POMS Manual Profile of Mood States. San Diego: Educational and Industrial Testing Service 1992. less adaptive cardiovascular responses to pain and pain-related stress. These findings hint at the potential utility of studying coping effects on the cardiovascular system in the context of chronic pain, given that substantial cardiovascular morbidity has been observed in some chronically painful conditions (8). A number of prospective epidemiological studies $(11,12)$ have now indicated that BP responses to the CP task predict the later development of hypertension and other important cardiovascular end points; future work in this area may benefit from assessment of pain-coping processes during the experience of acute pain. In summary, though these findings are exploratory in nature, the present investigation highlights the role that coping strategies may play in determining physiological, as well as affective and behavioural, responses to the experience of pain.

18. Sanders KA, Bruce NW. Psychosocial stress and treatment outcome following assisted reproductive technology. Hum Reprod 1999;14:1656-62.

19. Sherwood A, Allen MT, Fahrenberg J, Kelsey RM, Lovallo WR, van Doornen LJ. Methodological guidelines for impedance cardiography. Psychophysiology 1990;27:1-23.

20. al'Absi M, Wittmers LE, Ellestad D, et al. Sex differences in pain and hypothalamic-pituitary-adrenocortical responses to opioid blockade. Psychosom Med 2004;66:198-206.

21. al'Absi M, Petersen KL. Blood pressure but not cortisol mediates stress effects on subsequent pain perception in healthy men and women. Pain 2003;106:285-95.

22. Summers RL, Shoemaker WC, Peacock WF, Ander DS, Coleman TG. Bench to bedside: Electrophysiologic and clinical principles of noninvasive hemodynamic monitoring using impedance cardiography. Acad Emerg Med 2003;10:669-80.

23. van der Meer BJ, Vonk Noordegraaf A, Bax JJ, Kamp O, de Vries PM. Non-invasive evaluation of left ventricular function by means of impedance cardiography. Acta Anaesthesiol Scand 1999;43:130-4.

24. Sherwood A, Turner JR, Light KC, Blumenthal JA. Temporal stability of the hemodynamics of cardiovascular reactivity. Int J Psychophysiol 1990;10:95-8.

25. Edwards RR, Haythornthwaite JA, Sullivan MJ, Fillingim RB. Catastrophizing as a mediator of sex differences in pain: Differential effects for daily pain versus laboratory-induced pain. Pain 2004;111:335-41.

26. Gracely RH, Geisser ME, Giesecke T, et al. Pain catastrophizing and neural responses to pain among persons with fibromyalgia. Brain 2004;127:835-43.

27. Dixon KE, Thorn BE, Ward LC. An evaluation of sex differences in psychological and physiological responses to experimentally-induced pain: A path analytic description. Pain 2004;112:188-96. (Erratum in 2005;115:222).

28. Coghill RC, McHaffie JG, Yen YF. Neural correlates of interindividual differences in the subjective experience of pain. Proc Natl Acad Sci USA 2003;100:8538-42.

29. Affleck G, Tennen H, Urrows S, Higgins P. Neuroticism and the pain-mood relation in rheumatoid arthritis: Insights from a prospective daily study. J Consult Clin Psychol 1992;60:119-26.

30. Edwards RR, Fillingim RB, Maixner W, Sigurdsson A, Haythornthwaite J. Catastrophizing predicts changes in thermal pain responses after resolution of acute dental pain. J Pain 2004;5:164-70.

31. Van Damme S, Crombez G, Eccleston C. Disengagement from pain: the role of catastrophic thinking about pain. Pain 2004;107:70-6.

32. Janssen SA, Spinhoven P, Arntz A. The effects of failing to control pain: An experimental investigation. Pain 2004;107:227-33.

33. Arntz A, Claassens L. The meaning of pain influences its experienced intensity. Pain 2004;109:20-5.

34. Bruehl S, McCubbin JA, Wilson JF, Montgomery T, Ibarra P, Carlson CR. Coping styles, opioid blockade, and cardiovascular response to stress. J Behav Med 1994;17:25-40. 


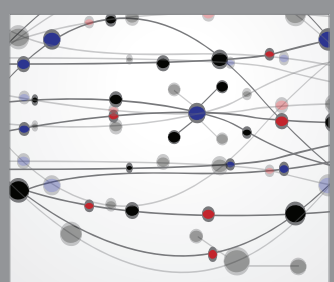

The Scientific World Journal
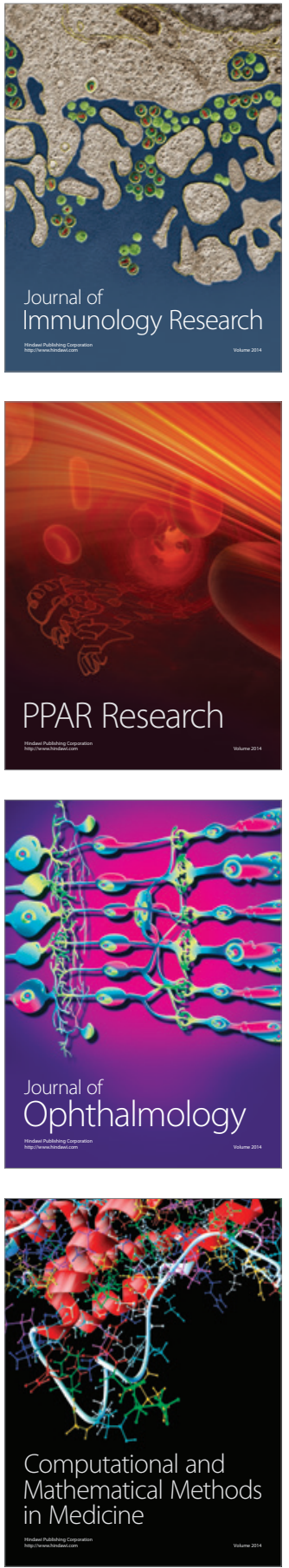

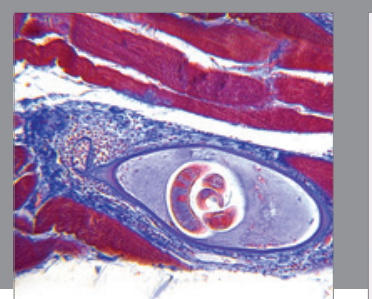

Gastroenterology Research and Practice

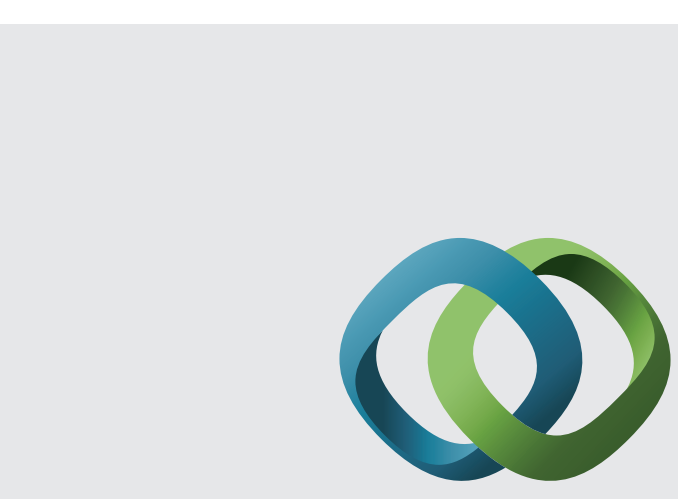

\section{Hindawi}

Submit your manuscripts at

http://www.hindawi.com
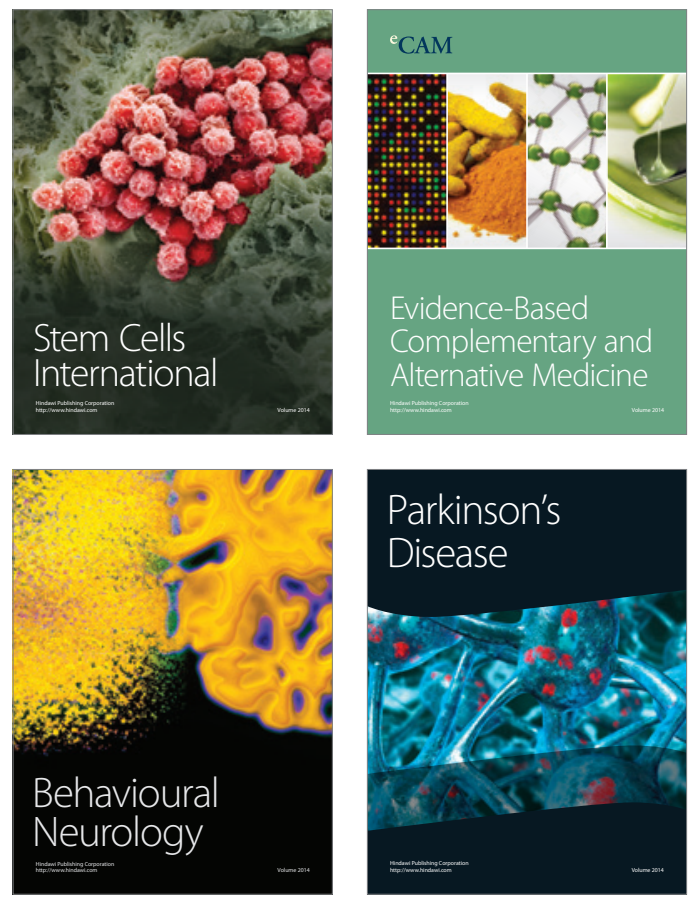
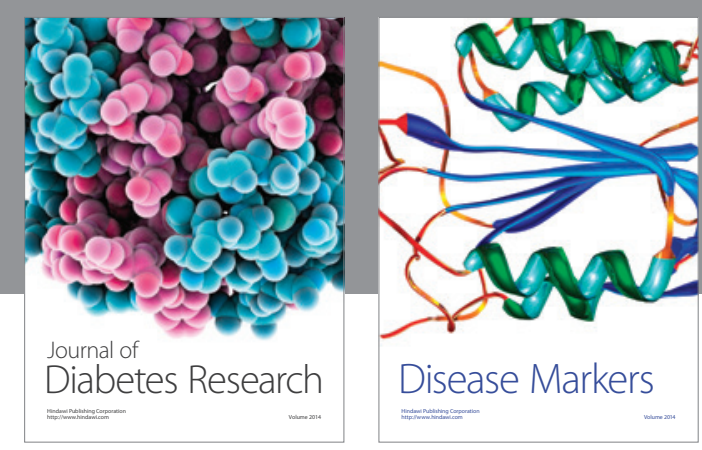

Disease Markers
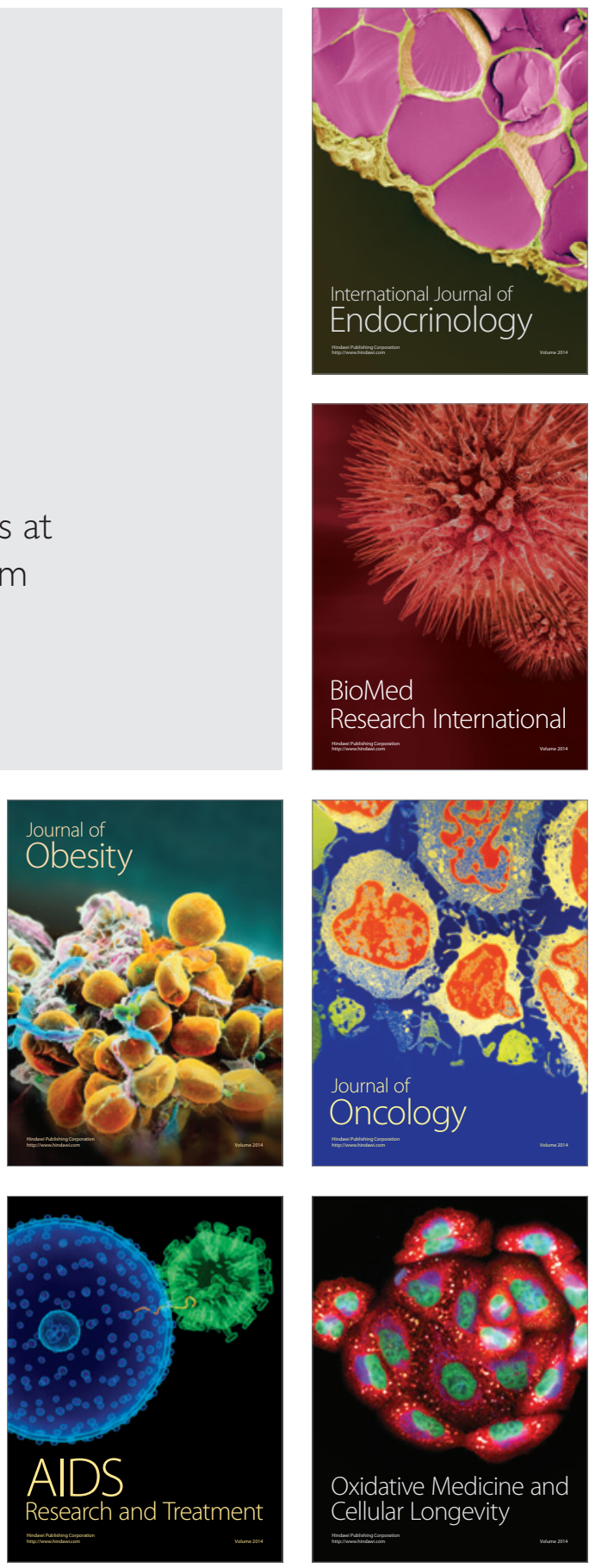